\title{
Interhospital transfer of the critically ill trauma patient: the potential role of a specialist transport team in a trauma system
}

\author{
G H McGinn, R E MacKenzie, J A Donnelly, E A Smith, C J Runcie
}

\begin{abstract}
A specialist transfer team based in the regional intensive therapy unit (ITU ) at the Western Infirmary, Glasgow, acts as a central interhospital retrieval team for Glasgow and the west of Scotland. The establishment of trauma systems has been proposed. This paper describes the activities of the specialist transfer team to illustrate the potential role of a central retrieval team within such a system.

( $f$ Accid Emerg Med 1996;13:90-92)
\end{abstract}

Key terms: critical care; transport; trauma

The care of the patient with trauma has received much attention since the publication of the working party report from the Royal College of Surgeons of England. ${ }^{1}$ It described the need for the establishment of trauma centres to improve patient management, and for high quality interhospital transfer. The problems that can occur during transfer are well documented and guidelines have been published. ${ }^{2}$ However, in a recent editorial ${ }^{3}$ the interhospital transfer of trauma patients was described as a neglected area and there is much evidence to support this. Two prospective studies eight years apart documented serious departures from recognised advanced trauma life support (ATLS) and American College of Surgeons and Physicians guidelines in $70 \%$ of patients undergoing interhospital transfer. ${ }^{45}$ Hypoxia and hypotension in transit have an independent and additive adverse effect on outcome in patients with head injuries. ${ }^{6}$ In a more recent study of neurosurgical emergencies, $58 \%$ of patients arrived at a regional neurosurgical centre with one or more of the following: hypotension, hypertension, hypoxaemia, or hypothermia. Simple monitoring standards were neglected, with no blood pressure measurement in $36 \%$ and no oximetry in 55\%. Only four patients left the receiving hospital with a systolic pressure less than $100 \mathrm{~mm} \mathrm{Hg}$, but 11 arrived in a hypotensive state. A study of 21 consecutive patients with multiple injuries transferred to a regional neurosurgical unit $^{8}$ found that only one patient was assessed by a doctor more senior than a registrar in any specialty before transfer.

It is clear that the standards of transfer require improvement. Oakley ${ }^{3}$ suggests two principal approaches. The first is a team training programme, and such a system has been established in the North West Midlands and is described by
Redmond..$^{10}$ The second is a central retrieval team. The Clinical Shock Study Group (CSSG) is a specialist transfer team based in a regional ITU and acts in part as a central retrieval team for a population of $2 \cdot 7$ million. The group consists of four post-fellowship registrars in anaesthesia and surgery dedicated to patient transfer. The activities of the group have been described previously. ${ }^{11} 12$ The standard of transfer by the CSSG is high. In the 20 years since its formation there has been only one death and the group has successfully transferred patients with APACHE scores greater than 22. The staff involved are all experienced registrars, dedicated to transfers, usually for a year or more. Such experience may be difficult to maintain in a team training programme.

The aim of this report is to describe the activities of the CSSG in the interhospital transfer of trauma patients to provide an informed view of the potential role of such a team in a trauma system.

\section{Methods}

Data were collected for all interhospital transfers performed by the CSSG involving patients who had suffered trauma, including isolated head injuries, from 1990 to July 1994. Information regarding patient age, sex, diagnosis, management, source of referral, destination, and transfer time was recorded at the time of transfer. Some of the patients with isolated head injuries were transferred to a general neurosurgical ward; all other patients were transferred to an intensive therapy unit (ITU). Duration of ITU stay and final outcome were obtained from ITU records.

\section{Results}

During the study period the CSSG was asked to transfer a total of 1305 patients. There were 97 multiple trauma patients and 95 with isolated head injuries. Three patients died before transfer and one died during transfer. Details of the patients are given in table 1 and figs 1 and 2. Transfer time (including outward journey, preparation of patient, and transfer to receiving unit) ranged from $30 \mathrm{~min}$ to $14 \mathrm{~h}$ (median $2 \mathrm{~h}$ ) for the head injury group and from 1 to $9.5 \mathrm{~h}$ ( median $3 \mathrm{~h}$ ) for the trauma group. Four transfers were by air, the remainder were all by road, with distances varying from 0.5 to 120 miles. The geography of the west of Scotland accounts for the longer transfers. The time of day that the transfers took place is shown in fig 3. 
Table 1 Patients transferred by the CSSG, 1990-fuly 1991

\begin{tabular}{rlll}
\hline Year & $\begin{array}{l}\text { Total number } \\
\text { of transfers }\end{array}$ & $\begin{array}{l}\text { Patients with } \\
\text { multiple trauma }\end{array}$ & $\begin{array}{l}\text { Patients with } \\
\text { isolated head injuries }\end{array}$ \\
\hline 1990 & 264 & $27(10 \%)$ & $27(10 \%)$ \\
1991 & 258 & $23(9 \%)$ & $24(9 \%)$ \\
1992 & 270 & $19(7 \%)$ & $19(7 \%)$ \\
1993 & 343 & $17(5 \%)$ & $17(5 \%)$ \\
To July 1994 & 170 & $7(4 \%)$ & $8(4 \cdot 7 \%)$ \\
Total & 1305 & 93 & 95 \\
\hline
\end{tabular}

All patients with multiple trauma were transferred to an ITU. Table 2 shows the monitoring and support procedures employed. The majority of patients with trauma $(56 \%)$ were transferred as acute cases from district general hospitals to tertiary referral centres with more appropriate expertise.

The neurosurgical facilities in the area covered by the CSSG are on a single site and 21 patients with trauma $(22 \%)$ were transferred there for neurosurgical investigation and management following treatment of other injuries. The CSSG also has a role transferring patients from the neurosurgical unit' to other ITUs for continuing intensive therapy to allow

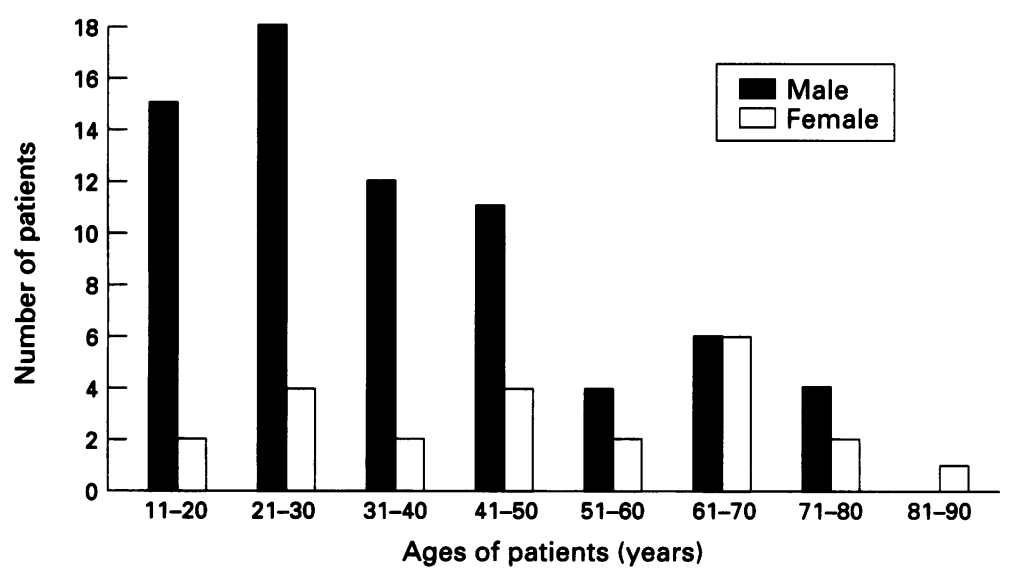

Figure 1 Ages of patients with multiple trauma transferred during the study period.

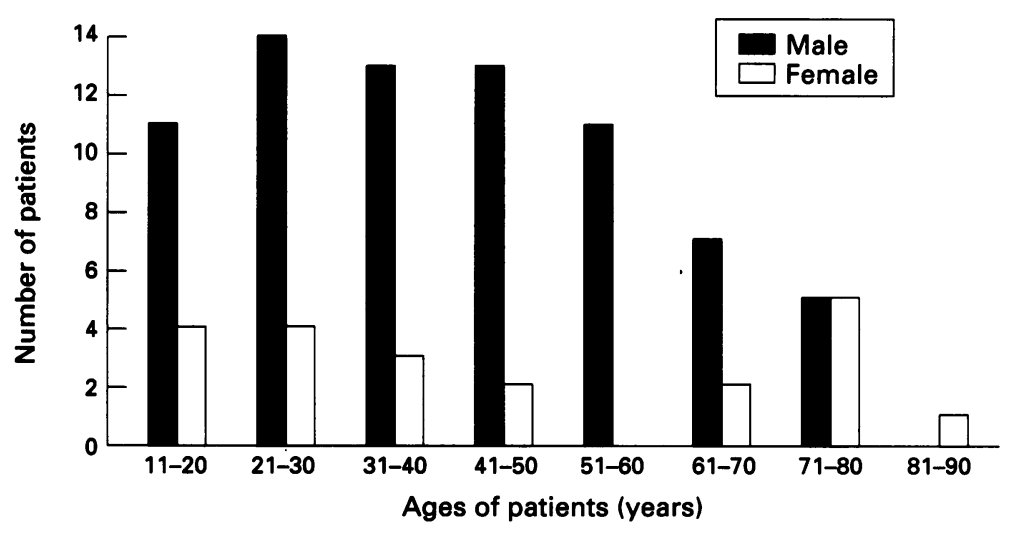

Figure 2 Ages of patients with head injuries transferred during the study period.

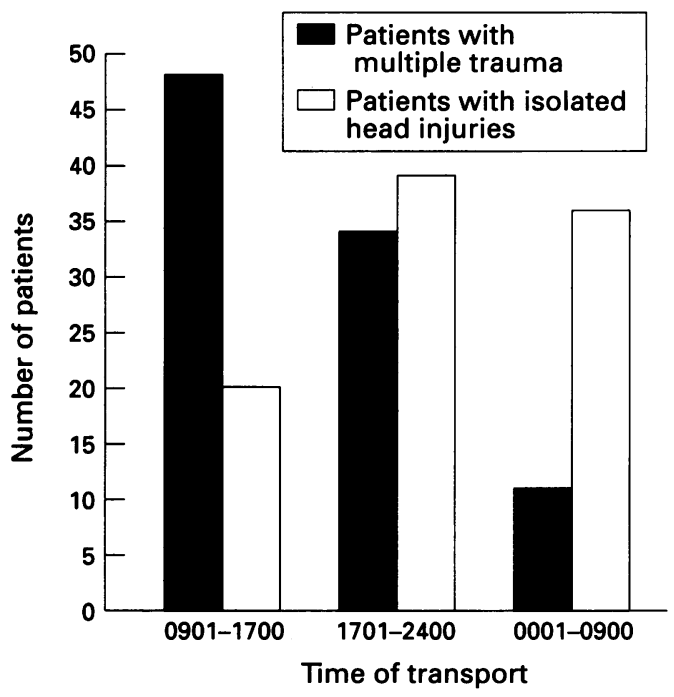

Figure 3 Time of day of transfers.

more appropriate use of neurosurgical intensive care beds. These are usually postoperative patients requiring prolonged mechanical ventilation. There were 19 such patients in this study.

In the group of patients with isolated head injuries, $49(52 \%)$ were transferred to a neurosurgical intensive care unit and $46(48 \%)$ to a general neurosurgical ward. Ninety two (97\%) were transferred from the CSSG base hospital, $84(88 \%)$ directly from accident and emergency ( $A \& E)$, and eight ( $8 \%$ ) from a general surgical ward after a period of observation. Of the remaining three patients in this group, two were from general ITUs near to the base hospital and one was an air transfer.

Patients were well prepared and resuscitated before transfer. Of the patients with multiple trauma, $83 \%$ were intubated and ventilated, and during the study period no patients required intubation in transit. The level of monitoring is high (table 2). All patients had ECG and pulse oximetry, and in the case of multiple trauma $96 \%$ had invasive blood pressure monitoring, which has been shown to be superior to indirect pressure monitoring during transport. ${ }^{13}$

The ITU outcome of patients transferred to general and neurosurgical ITUs was determined (table 3 ). The median stay in general ITU was $6 \mathrm{~d}$ (range $0 \cdot 5-30 \mathrm{~d}$ ) with an ITU mortality of $11(12 \%)$. The median stay in the neurosurgical ITU was $2 \mathrm{~d}$ (range 0.5 to $14 \mathrm{~d}$ ) with an ITU mortality of eight (8\%).

Of the three patients who died before transfer, two succumbed before arrival of the transfer team and the third had an asystolic cardiac arrest 15 min after arrival of the team at referring hospital. One patient died during

Table 2 Monitoring and support procedures during transfer

\begin{tabular}{llll}
\hline Monitoring/support & $\begin{array}{l}\text { Patients with } \\
\text { multiple trauma } \\
(n=93)\end{array}$ & $\begin{array}{l}\text { Patients with isolated head } \\
\text { injuries transferred to a } \\
\text { neurosurgical ITU } \\
(n=49)\end{array}$ & $\begin{array}{l}\text { Patients with isolated head } \\
\text { injuries transferred to a } \\
\text { general neurosurgical ward } \\
(n=46)\end{array}$ \\
\hline ECG and pulse oximetry & $93(100 \%)$ & $49(100 \%)$ & $46(100 \%)$ \\
Invasive blood pressure & $89(96 \%)$ & $38(78 \%)$ & $2(4 \%)$ \\
Central venous pressure & $53(57 \%)$ & $3(6 \%)$ & $0(0 \%)$ \\
Pulmonary capillary wedge pressure & $4(4 \%)$ & $0(0 \%)$ & $0(0 \%)$ \\
Intermittent positive pressure ventilation & $77(83 \%)$ & $40(82 \%)$ & $0(0 \%)$ \\
\hline
\end{tabular}


Table 3 ITU outcome of transferred patients

\begin{tabular}{lllll}
\hline & $\begin{array}{l}\text { Median } \\
\text { duration } \\
\text { of ITU stay }\end{array}$ & $\begin{array}{l}\text { Number of patients } \\
\text { who died within } \\
24 \text { h of admission }\end{array}$ & $\begin{array}{l}\text { Number of patients } \\
\text { who died in } \\
\text { ITU }\end{array}$ & $\begin{array}{l}\text { Number of patients } \\
\text { discharged from } \\
\text { ITU }\end{array}$ \\
\hline Patients transferred to a general ITU $(\mathrm{n}=93)$ & 6 days & $2(2 \%)$ & $11(12 \%)$ & $82(88 \%)$ \\
Patients transferred to a neurosurgical ITU $(\mathrm{n}=95)$ & 2 days & $2(2 \%)$ & $8(8 \%)$ & $87(92 \%)$ \\
\hline
\end{tabular}

transfer. This 40 year old man fell while climbing on his own. He sustained a head injury, a fractured pelvis, and bilateral haemopneumothoraces with multiple fractured ribs. He was admitted to an isolated district general hospital with a Glasgow coma scale score of 3, and was intubated, ventilated, underwent a laparotomy with splenectomy, and had bilateral chest drains inserted. Before transfer his pupils were fixed and dilated. It was concluded that his prognosis was poor but that he did require transfer to the regional neurosurgical centre. During transfer he became bradycardic and then asystolic, both unresponsive to treatment. It was presumed that he had suffered fatal brain shift, and it seems likely that his death was inevitable.

\section{Discussion}

The Working Party Report from the Royal College of Surgeons of England ${ }^{1}$ discussed the provision of services for patients with major injuries. It emphasised the need for improvement, including the establishment of trauma centres with a concentration of expertise, as this has been shown to improve outcome. Redmond's pilot study, ${ }^{9}{ }^{10}$ found that $30 \%$ of patients with major injuries were transferred from other hospitals to the trauma centre. The development of trauma centres would increase the number of patients with major injuries undergoing interhospital transfer and both the working party report ${ }^{1}$ and a recent editorial ${ }^{3}$ emphasised the need for appropriate standards. The same editorial proposed two methods of providing suitable staff. The first was a team training programme with all hospitals involved having a group drawn from doctors, nurses, and paramedics, some of whom would be on duty at any one time to transfer patients to the trauma centre. This has the advantage of providing a transfer system at little extra cost. However, with continual staff turnover it may be difficult to maintain a large enough pool of trained individuals. The second method is a central retrieval team. This would be a group of individuals dedicated to the transfer of patients and continually available, based either at a regional ITU or trauma centre. In the North West Midlands trauma system, ${ }^{9} 10$ Redmond suggests that the proportion of major trauma patients transferred directly to the trauma centre by ambulance crews and paramedics is high $(70 \%)$ and is likely to increase. This may not be the case in other areas, particularly with a lower population density. There will always be a proportion of patients with major injuries who require interhospital transfer, and therefore there will be a need for a transfer team.

During the study period there were 1305 transfers; of these 53 had multiple trauma and were transferred from district general hospitals to tertiary referral centres for further management. The proportion of acute trauma that this represents is not clear. The CSSG does not calculate an injury severity score (ISS) for trauma patients it transfers. It is therefore impossible to make comparisons of patient numbers in the categories described by Oakley. The closest comparison is probably patients transferred to the trauma centre with an ISS greater than 15 without a predominant head injury. There were 13 such transfers in the North West Midlands in one year with a population base of 1.7 million. By comparison the CSSG transferred 53 multiple trauma patients between hospitals over four years and six months with a population base of $2 \cdot 7$ million.

The use of a central retrieval team in the context of multiple trauma would appear reasonable. In our experience there are no delays and coverage may be reasonable in terms of the proportion of patients transferred. The standards are high, with experienced staff, good equipment, and good results. In the case of isolated head injuries the service is restricted to the base hospital; the other hospitals in the area have their own arrangements for the transfer of these patients to prevent delay.

We conclude that a central retrieval team is a practical option for the interhospital transfer of a wide range of patients including those with major trauma, and could be integrated into a system with a trauma centre. In the establishment of trauma systems in the future, the use of a central retrieval team should be considered. The concentration of expertise and experience may outweigh the extra cost involved.

1 Report of the working party on the management of patients with major injuries. London: Royal College of Surgeons with major injuries.

2 Guidelines committee. Guidelines for the transfer of critically ill patients. Crit Care Med 1993;21:931-7.

3 Oakley PA. The need for standards for inter-hospital transfer. Anaesthesia 1994;49:565-6.

4 Hicks TC, Danzie DF, Thomas DM, Flint LM. Resuscitation and transfer of trauma patients: prospective study. Ann Emerg Med 1982;11:296-9.

5 Martin GD, Cogbill TH, Landercasper J, Strutt PJ. Prospective analysis of rural interhospital transfer of injured patients to a referral trauma centre. $\mathcal{F}$ Trauma 1990;30:1014-20.

6 Gentleman D, Jennett B. Hazards of interhospital transfer of comatose head injured patients. Lancet 1981;ii:853-5.

7 Munro HM, Laycock JRD. Interhospital transfer: standards for neurosurgical emergencies. Br f Intensive Care 1993; 3:210-14.

8 Lambert SM, Willet $\mathrm{K}$. Transfer of multiply injured patients for neurosurgical opinion: a study of the adequacy of assessment and resuscitation. Injury 1993;24:333-6.

9 Redmond AD. The North Staffordshire trauma system. $\mathcal{F} R$ Coll Surg Edinb 1993;38:248-50.

10 Redmond AD. A trauma centre for the United Kingdom. Ann Emerg Med 1993;22:1584-8.

11 Reeve WG, Runcie CJ, Reidy J, Wallace PGM. Current practice in transferring critically ill patients among practice in transferring critically ill patients among
hospitals in the west of Scotland. BMf 1990;300:85-7.

12 Runcie CJ, Reeve J, Wallace PGM. Secondary transport of the critically ill adult. Clin Intensive Care 1991;2:217-25.

13 Runcie CJ, Reeve WG, Reidy J, Dougall JR. Blood pressure measurement during transport. Anaesthesia 1990;45: 659-65. 